\title{
WEAK-HYPERLATTICES DERIVED FROM FUZZY CONGRUENCES
}

\author{
Blériot Blaise Njionou Koguep \\ Department of Mathematics and Computer science \\ University of Dschang, BP 67 \\ e-mail: koguep@yahoo.com \\ AND \\ Celestin Lele \\ Department of Mathematics and Computer science \\ University of Dschang, BP 67 \\ e-mail: celestinlele@yahoo.com
}

\begin{abstract}
In this paper we explore the connections between fuzzy congruence relations, fuzzy ideals and homomorphisms of hyperlattices. Indeed, we introduce the concept of fuzzy quotient set of hyperlattices as it was done in the case of rings [19]. We prove that a fuzzy congruence induces a fuzzy ideal of the fuzzy quotient hyperlattice. In particular, we establish necessary and sufficient conditions for a zero-fuzzy congruence class to be a fuzzy ideal of a hyperlattice.
\end{abstract}

Keywords: hyperlattice, ideal, prime ideal, fuzzy ideal, fuzzy prime ideal, fuzzy congruence relation.

2010 Mathematics Subject Classification: 06B10, 03E72, 06D72, 06B75, $08 \mathrm{~A} 72$.

\section{REFERENCES}

[1] R. Ameri, M. Amiri-Bideshki, A.B. Saeid and S. Hoskova-Mayerova, Prime filters of hyperlattices, An. Şt. Univ. Ovidius Constanţa, Ser. Matematica 24 (2016) 15-26. doi:10.1515/auom-2016-0025

[2] M. Attallah, Completely Fuzzy Prime Ideals of distributive Lattices, The Journal of Fuzzy Mathematics 8 (2000) 151-156. 
[3] M. Bakhshi and R.A. Borzooei, Lattice structure on fuzzy congruence relations of a hypergroupoid, Inform. Sci. 177 (2007) 3305-3313.

[4] R.A. Borzooei, M. Bakhshi and Y.B. Jun, Fuzzy congruence relations on hyper BCK-algebras, J. Fuzzy Math. 13 (2005) 627-636.

[5] I.P. Cabrera, P. Cordeo, G. Gutiérrez, J. Martinez and M. Ojeda-Aciego, Fuzzy congruence relations on nd-groupoids, Int. J. Comput. Math. 86 (2009) 1684-1695. doi:10.1080/00207160902721797

[6] I.P. Cabrera, P. Cordeo, G. Gutiérrez, J. Martinez and M. Ojeda-Aciego, Congruence relations on some hyperstructures, Annals of Mathematics and Artificial Intelligence 2009 (Accessible from http://sevein.matap.uma.es/ aciego/amai.pdf).

[7] P. Corsini and V. Leoreanu, Application of Hyperstructure Theory (Kluwer Academic Publishers, Advances in Mathematics, Vol. 5, Boston, Dordrecht, London, 2003).

[8] B.A. Davey and H.A. Priestley, Introduction to Lattices and Order (Cambridge University Press, Second edition, Cambridge, 2002).

[9] J. Jakubik, On strong superlattices, Math. Slovaca 44 (1994) 131-138.

[10] B.B.N. Koguep, C. Lele and J.B. Nganou, Normal hyperlattices and pure ideals of hyperlattices, Asian-European J. Math. 9 (2016) 1650020 (14 pages). doi:10.1142/S1793557116500200

[11] B.B.N. Koguep, C. Nkuimi and C. Lele, On fuzzy ideals of hyperlattice, Int. J. Algebra 2 (2008) 739-750.

[12] M. Konstantinidou and J. Mittas, An introduction to the theory of Hyperlattices, Mathematica Balcanica 7 (1997) 187-193.

[13] F. Marty, Sur une généralisation de la notion de groupe, $8^{\text {ième }}$ Congrès des Mathématiciens Scandinaves, Stockholm (1934) 45-49.

[14] V. Murali, Fuzzy equivalence relations, Fuzzy Sets and Systems 30 (1989) 155-163.

[15] A. Rahnamai-Barghi, The prime ideal theorem for distributive hyperlattices, Ital. J. Pure and Appl. Math. 10 (2001) 75-78.

[16] A. Rahnamai-Barghi, The prime ideal theorem and semiprime ideals in meethyperlattices, Ital. J. Pure and Appl. Math. 5 (1999) 53-60.

[17] S. Rasouli and B. Davvaz, Lattice derived from hyperlattices, Comm. in Algebra 38 (2010) 2720-2737.

[18] S. Rasouli and B. Davvaz, Construction and spectral topology on hyperlattice, Mediterr. J. Math. 7 (2010) 249-262.

[19] S. Yu-Qiang and Z. Cheng-Yi, Congruence on the semirings with reversible addition, Intern. J. Pure Appl. Math. 26 (2006) 155-163.

[20] U.M. Swamy and D. Viswanadha Raju, Fuzzy ideals and congruences of Lattices, Fuzzy sets and Systemes 95 (1998) 249-253. 
WEAK-HYPERLATTICES DERIVED FROM FUZZY CONGRUENCES

[21] L.A. Zadeh, Fuzzy sets, Information and Control 8 (1965) 338-353.

Received 14 September 2016

Revised 6 December 2016 
